\title{
ANALISA KEGAGALAN MATERIAL SA-210C PADA APLIKASI BOILER STEAM PIPE
}

\author{
Andi Rinaldi Hasan \\ Pasca Sarjana Teknik Mesin Universitas Trisakti \\ Email : andi.rinaldi@indonesiapower.co.id
}

\begin{abstract}
The purpose of this study was to determine the cause of pipe failure in super saturated area boilers. The research method begins with the collection of chronological data on material failure, operating data collection and material sampling. After material sampling is carried out, photos of failed material are subsequently carried out, thickness measurements, hardness testing, metallographic testing and internal pipe pressure calculations. The results showed that the outside of the pipe had erosion corrosion due to a reduction in thickness of the pipe, especially location 1. Thickening was caused by high pressure auxiliary steam bursts from the sootblower equipment which lasted for a long time at the pipe surface, resulting in $\mathrm{Fe}+\mathrm{O} \mathrm{FeO}$ reaction. FeO formed at the beginning will be released due to high-pressure auxiliary steam bursts and at the same time the auxiliary steam burst reacts chemically again to form FeO. Because of the repeated processes, the pipe thickness slowly decreases. As a result of the depletion, the pipe reaches a critical value so it is unable to withstand the pressure from the pipe and eventually fails. The failure factor, supported by some data on boiler water quality and continuous operating pressure from sootblower that affect erosion corrosion. Changes in microstructure also affect the decrease in hardness in the material which can be seen from the size and shape of the grain.
\end{abstract}

Keywords: steam boilers, failure, erosion corrosion, material testing, permissible pipe internal pressure calculation

\begin{abstract}
Abstrak
Tujuan penelitian ini adalah untuk mengetahui penyebab kegagalan pipa pada ketel uap daerah super jenuh (superheat). Metode penelitian diawali dengan pengumpulan data kronologi kegagalan material, pengumpulan data operasi dan pengambilan sampel material. Setelah pengambilan sampel material dilakukan, untuk selanjutnya dilakukan foto fisik material gagal, pengukuran ketebalan, pengujian kekerasan, pengujian metalografi dan perhitungan tekanan internal pipa. Hasil penelitian menunjukkan, bagian luar pipa telah mengalami korosi erosi karena adanya pengurangan ketebalan pada pipa, terutama lokasi 1 . Pengurangan ketebalan disebabkan semburan uap bantu bertekanan tinggi dari peralatan sootblower yang berlangsung lama pada permukaan pipa dilokasi 1 , sehingga menghasilkan reaksi $\mathrm{Fe}+\mathrm{O} \mathrm{FeO}$. $\mathrm{FeO}$ yang terbentuk diawal akan terlepas akibat semburan uap bantu bertekanan tinggi dan pada saat yang sama semburan uap bantu bereaksi kimia kembali membentuk FeO. Karena proses yang berulang-ulang, maka secara perlahan ketebalan pipa berkurang. Akibat penipisan tersebut, pipa mencapai nilai kritis sehingga tidak mampu menahan tekanan dari dalam pipa dan akhirnya mengalami kegagalan/ pecah. Faktor kegagalan tersebut, didukung dengan beberapa data kualitas air ketel uap dan tekanan operasi terus menerus dari sootblower yang mempengaruhi terjadinya korosi erosi. Perubahan struktur mikro juga berpengaruh terhadap penurunan kekerasan pada material yang dapat dilihat dari ukuran dan bentuk butir.
\end{abstract}

Kata kunci: ketel uap, kegagalan, korosi erosi, pengujian material, perhitungan tekanan internal pipa yang diizinkan

\section{Pendahuluan}

Saat ini Indonesia mengalami permasalahn energi yang cukup serius, antara lain kurangnya pasokan listrik. Hal ini menyebabkan seringnya pemadaman bergilir yang terjadi, terutama diluar pulau Jawa. Terus meningkatnya kebutuhan listrik Indonesia terjadi sejalan dengan peningkatan pertumbuhan ekonomi nasional, dengan perkiraan pertumbuhan mencapai $7,3 \%$ pertahun selama 10 tahun, terhitung dari 2009-2019 [Muchlis, 2004].

Sementara itu potensi batubara Indonesia sebagai bahan bakar pembangkit sekitar 105 milyar ton, namun 60\% (54,6 milyar ton) adalah batubara muda yang memiliki nilai kalor rendah dengan nilai kalori $\leq 4000 \mathrm{kkal} / \mathrm{kg}$. Pemanfaatan langsung batubara jenis ini 
Journal of Mechanical Engineering and Mechatronics

ISSN: 2527-6212, Vol. 3 No. 1

(c) 2018 Pres Univ Press Publication, Indonesia

sebagai bahan bakar Pembangkit Listrik Tenaga Uap (PLTU) akan sangat mahal karena membutuhkan ukuran ketel uap (boiler) yang lebih besar sebagai pembangkit listrik. Disamping itu juga akan dihasilkan emisi $\mathrm{CO} 2$ yang jauh lebih besar per kilowatt energi output dibandingkan dengan batubara kalori menengah atau dengan batubara kalori tinggi.

Sejalan dengan komitmen pemerintah untuk meningkatkan taraf kehidupan rakyat melalui suplai energi listrik yang andal, murah dan menyeluruh, maka pada tahun 2006 telah dikeluarkan Peraturan Presiden No. 71 yang menugaskan Perusahaan Listrik Negara (PLN) untuk membangun pembangkit listrik dengan Jalur Program Percepatan 10,000 MW tahap-1 dan 10,000 MW tahap-2. Pada pembangunan tahap-1, secara keseluruhan terdiri dari PLTU berbahan bakar batubara, sedangkan tahap-2 didominasi pembangunan pembangkit listrik energi terbaharukan, yakni Pembangkit Listrik Tenaga Panas bumi (PLTP), Pembangkit Listrik Tenaga Gas-Uap (PLTGU) dan Pembangkit Listrik Tenaga Air (PLTA).

PLTU Lontar, merupakan salah satu proyek pembangunan PLTU tahap-1 dengan desain dan manufaktur ketel uap berasal dari Cina. Permasalahan yang sering dijumpai pada ketel uap ditemukannya kebocoran pipa pada ketel uap tersebut. Penelitian ini dilakukan untuk analisa kegagalan yang terjadi disalah satu unit PLTU Lontar tersebut.

\section{Bahan Dan Metoda}

\subsection{Diskripsi Objek Studi Ketel Uap Dengan Kapasitas 300 MW.}

Gambar 1 memperlihatkan bagian-bagian ketel uap dengan kapasitas 300 MW sesuai desain.

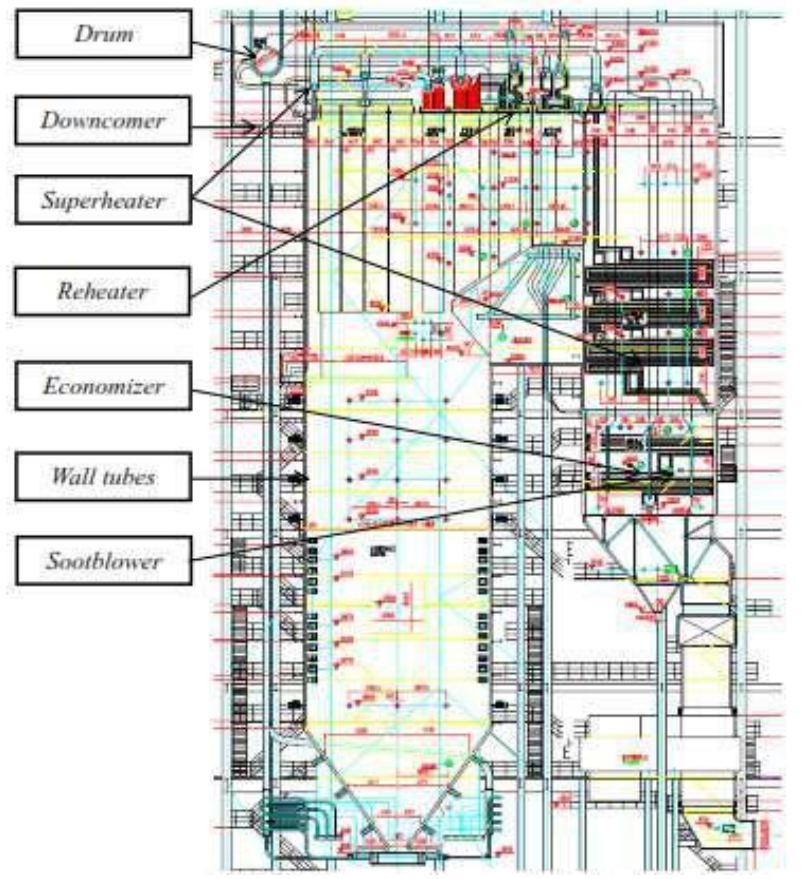

Gambar 1. Bagian-bagian ketel uap dengan kapasitas 300 MW (Design Case)

Siklus yang terjadi pada PLTU ini adalah sebagai berikut.

Uap hasil produksi boiler dengan temperatur dan tekanan tertentu digunakan untuk memutar turbin uap sehingga menghasilkan daya mekanik dan selanjutnya dikopel langsung dengan generator listrik. Terdapat 3 tingkat turbin uap yaitu turbin tekanan tinggi (HPT), turbin tekanan menengah (IPT) dan turbin tekanan rendah (LPT). Uap panas dari boiler pertama kali digunakan untuk memutar HPT. Setelah keluar dari HPT uap panas dipanaskan lagi di reheater dan kemudian dialirkan ke IPT. Setelah dari IPT, uap panas langsung menuju LPT. 
Pembangkit ini mempunyai konfigurasi Feeed Water Heater (FWH) $3-1-4$ yaitu 3 FWH pada tekanan tinggi, 1 deaerator dan $4 \mathrm{FWH}$ pada tekanan rendah. Dari LPT, uap dikondensasikan di dalam kondensor memakai air pendingin yang berasal dari air laut. Setelah uap terkondensasi menjadi air kondensat, air kondensat dialirkan menuju LP heater oleh $\mathrm{p}$ o m p a k o n d e n s a t untuk dipanaskan, kemudian masuk ke deaerator. Dari deaerator air tersebut dipanaskan kembali di HP heater melalui BFP (Boiler Feed Pump). Setelah dari HP heater, air tersebut masuk ke economizer lalu ke water drum. Demikian siklus terjadi secara terus-menerus dan berulang-ulang, sehingga siklus ini dinamakan siklus tertutup.

\subsection{Kategori Kegagalan Pada Pipa Ketel Uap}

\subsubsection{Tekanan pecah}

Tekanan pecah umumnya dikarenakan overheating yang dapat diartikan sebagai kegagalan yang disebabkan pengoperasian ketel uap pada temperatur diatas desain selama waktu tertentu. Overheating dihasilkan oleh kondisi yang abnormal seperti; hilangnya aliran pendingin atau temperatur ruang bakar ketel uap yang terlalu tinggi.

\subsubsection{Temperatur mulur tinggi}

Kerusakan akibat mulur, umumnya diawali retak aksial. Retak muncul pada arah aksial atau longitudinal tegak lurus dengan principle hoop stress.

\subsubsection{Korosi}

Permasalahan yang sering dijumpai pada pipa ketel uap pada area superheater adalah korosi (water/fire side) dan erosi [3].

\subsubsection{Korosi terlokalisasi}

Korosi terlokalisasi merupakan bentuk korosi yang membentuk lubang-lubang kecil pada logam. Penyebab utama korosi ini adalah kurangnya oksigen disuatu daerah yang kecil, dimana daerah ini menjadi semakin anodik,sedangkan daerah dengan kelebihan oksigen, menjadi semakin katodik sehingga menimbulkan korosi galvanik yang terlokalisasi.

\subsubsection{Degradasi mikrostruktur}

Merupakan mekanisme kerusakan yang dapat mengakibatkan kegagalan dengan beberapa proses, seperti mulur (creep) dan lelah (fatigue), sehingga menyebabkan pengurangan kekuatan dari material.

\subsubsection{Hydrogen damage}

Hydrogen damageterjadi akibat berdifusinya atom hidrogen kedalam logam yang kemudian bereaksi dengan karbon dalam Fe3C untuk membentuk metana, sehingga metana tersebut akan mengeleminasi pearlit yang ada. Karakteristik kegagalan yaitu terjadinya dekarburisasi dan retakan merambat dari Internal Diameter (ID) ke Outer Diameter (OD).

\subsection{Metodologi}

1. Pengumpulan data kronologi kegagalan material dan operasi berdasarkan data-data log sheet yakni data kualitas air ketel uap dan data operasi ketel; uap meliputi tekanan uap utama (main steam pressure), tekanan ruang bakar (furnance pressure) dan tekanan uap bantu saat pengoperasian soot blower.

2. Pengambilan sampel material untuk dilakukan foto fisik material gagal dan pengujian material.

3. Pengujian material dilakukan pada sampel material gagal dan sampel material standar untuk dapat ditemukan perbedaan antara kedua sampel material tersebut. Adapun pengujian material sampel ini, yaitu:

a. Pengukuran diameter dan ketebalan dengan menggunakan micrometer

b. Pengujian komposisi kimia material

c. Pengujian metalografi material 
Journal of Mechanical Engineering and Mechatronics

ISSN: 2527-6212, Vol. 3 No. 1

(C) 2018 Pres Univ Press Publication, Indonesia

d. Pengujian keekrasan material

e. Perhitungan tekanan internal yang diizinkan akibat perubahan ketebalan

4. Perhitungan tekanan internal dilakukan untuk mengetahui tekanan maksimum yang diizinkan terhadap ketebalan suatu pipa berdasarkan persamaan berikut [ASME

Boiler \& Pressure Vessel Code, Section VIII, Division I, 2007].

$t m=\frac{P \times D}{2 x((S \times E q)+(P \times Y))}+c$

dimana:

$\mathrm{tm}=$ tebal dinding pipa (in)

$P=$ tekanan internal relatif (psig) $D=$ diameter luar pipa(in) Eq =faktor kualitas

$\mathrm{S}=$ tegangan yang diijinkan (hot stress), $\mathrm{Y}=$ koefisien sifat material $\mathrm{C}=$ mechanical

+ corrosion+ erosion allowances 0.02 in

Adapun penentuan nilai faktor kualitas (Eq), tegangan yang diizinkan (S) dan koefisien sifat material $(\mathrm{Y})$ ditentukan berdasarkan tabel standar untuk perhitungan tekanan internal.

5. Analisa data

Tabel 1. Data operasi ketel uap

\begin{tabular}{|c|c|c|c|}
\hline Anitir Maded & \multicolumn{3}{|c|}{ Doles $174-1113$} \\
\hline Mannfactiret & \multicolumn{3}{|c|}{ sxatixus } \\
\hline \multirow{4}{*}{ Supvethestad Shaun } & Mais Stamin Fum & Mre & 174 \\
\hline & Main Strum Tanp. & z & 540 \\
\hline & Main Stam Has & 1h & 1025 \\
\hline & Mtentral & \multicolumn{2}{|c|}{$54.210 \mathrm{C}$} \\
\hline \multirow{2}{*}{ Sandbawet } & Woriage persure (Liag S8) & $\mathrm{MP}=$ & $1-1,3$ \\
\hline & Ienpeinhum & $\tau$ & 370 \\
\hline \multirow{3}{*}{ Reteral Steam } & Bechoul brost Outiet Prem. & MP: & $3,7 y 3,53$ \\
\hline & 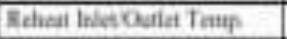 & $\bar{T}$ & 32245 \\
\hline & Matenal & \multicolumn{2}{|c|}{ 12CrMtov } \\
\hline \multirow{2}{*}{ Soethlawer } & 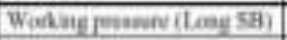 & $\mathrm{MP}$ & $0 \pi-1$ \\
\hline & Tenperabie & $\tau$ & 350 \\
\hline \multirow{4}{*}{ Paranater } & Flue Cas Out Teme & $\bar{\tau}$ & 150 \\
\hline & Food Wonet Temp. & $\mathrm{x}$ & 274 \\
\hline & Fovd Waner Fow & 16 & $\mathrm{kan}$ \\
\hline & Druminos & MP: & 14,75 \\
\hline \multirow{3}{*}{ 5pay Warer } & In Staye Syper Healar & th & 15,7 \\
\hline & 2nd Stant Siper Ileatia & ith & 3,35 \\
\hline & Rechalier & in & 1,5 \\
\hline Design I finciency & & 8 & 935 \\
\hline Mlauifacture Yan & & Yeal & 2964 \\
\hline Fins Symanon & & Yeat & 21111 \\
\hline Somiendan & & Yvar & 3 \\
\hline Eallens & HSansthatest & & Iasion \\
\hline $\begin{array}{l}\text { Calmifie Valies of } \\
\text { Coel }\end{array}$ & (M/Recoved Basis) & Kealle & $3900-4500$ \\
\hline
\end{tabular}

Tabel 2. Data pemakaian air pengisi saat terjadi kegagalan

\begin{tabular}{|c|c|c|c|c|c|c|}
\hline \multirow{2}{*}{$\begin{array}{l}\text { Ta } n \\
\text { gga I }\end{array}$} & \multirow{2}{*}{ Lo a d } & \multirow{2}{*}{ MSP } & \multirow{2}{*}{ MST } & \multicolumn{3}{|c|}{$\mathrm{FWF}(\mathrm{t} / \mathrm{h})$} \\
\hline & & & & No rma I & Le a k & Deviasi \\
\hline 16 & 250,81 & 14,83 & 533,59 & 737,83 & 760,52 & 22,69 \\
\hline 17 & 250,31 & 14,33 & 537,59 & 737,83 & 763,97 & 26,14 \\
\hline 18 & 250,26 & 14,58 & 533,55 & 736,34 & 765,62 & 29,28 \\
\hline 19 & 250,28 & 14,83 & 532,55 & 737,45 & 762,93 & 25,48 \\
\hline 20 & 252,74 & 14,58 & 535,53 & 740,50 & 768,98 & 28,48 \\
\hline 21 & 253,16 & 15,33 & 534,53 & 743,12 & 771,48 & 28,36 \\
\hline 22 & 250,37 & 14,75 & 533,53 & 739,51 & $767,87^{\circ}$ & 28,36 \\
\hline 23 & 250,95 & 14,8 & 534,55 & 741,15 & 784,17 & 43,02 \\
\hline 24 & & & & & & \\
\hline
\end{tabular}


Tabel 3. Data sistem air penambahan saat terjadi kegagalan

\begin{tabular}{|c|c|c|c|c|c|c|}
\hline Ta n gga I & Lo a d & MSP & MST & \multicolumn{3}{|c|}{ Ma ke -Up } \\
\hline & & & & No rma I & Le a k & De vi a si \\
\hline 16 Jan. & 250,81 & 14,83 & 533,59 & 18,98 & 32,62 & 13,64 \\
\hline 17 Jan. & 250,31 & 14,33 & 537,59 & 19,12 & 35,53 & 16,41 \\
\hline 18 Jan. & 250,26 & 14,58 & 533,55 & 20,08 & 35,53 & 15,45 \\
\hline 19 Jan. & 250,28 & 14,83 & 532,55 & 21,99 & 42,02 & 20,03 \\
\hline 20 Jan. & 252,74 & 14,58 & 535,53 & 20,98 & 43,23 & 22,25 \\
\hline 21 Jan. & 253,16 & 15,33 & 534,53 & 23,87 & 45,66 & 21,79 \\
\hline 22 Jan. & 250,37 & 14,75 & 533,53 & 21,56 & 42,67 & 21,11 \\
\hline 23 Jan. & 250,95 & 14,8 & 534,55 & 20,71 & 53,68 & 32,97 \\
\hline 24 Jan. & \multicolumn{7}{|c|}{ STOP UNI T } \\
\hline
\end{tabular}

Tabel 4. Data pemakaian batubara saat terjadi kegagalan

\begin{tabular}{|r|r|r|r|r|r|r|}
\hline Ta n gga & Lo a d & MSP & MST & \multicolumn{3}{|c|}{ Co a I } \\
\hline & & & & No rma & Le a $~$ & De vi a s \\
\hline 16 Jan. & 250,81 & 14,83 & 533,59 & 153,48 & 157,74 & 4,26 \\
\hline 17 Jan. & 250,31 & 14,33 & 537,59 & 156,48 & 165,88 & 9,40 \\
\hline 18 Jan. & 250,26 & 14,58 & 533,55 & 155,71 & 185,84 & 30,13 \\
\hline 19 Jan. & 250,28 & 14,83 & 532,55 & 160,74 & 166,16 & 5,42 \\
\hline 20 Jan. & 252,74 & 14,58 & 535,53 & 163,88 & 169,2 & 5,32 \\
\hline 21 Jan. & 253,16 & 15,33 & 534,53 & 165,48 & 179,2 & 13,72 \\
\hline 22 Jan. & 250,37 & 14,75 & 533,53 & 155,76 & 169,32 & 13,56 \\
\hline 23 Jan. & 250,95 & 14,8 & 534,55 & 165,72 & 173,27 & 7,55 \\
\hline 24 Jan. & \multicolumn{5}{|c|}{ STOP UNI T } \\
\hline
\end{tabular}

Berdasarkan tabel 2-4 terlihat data-data sebelum terjadinya kegagalan material pada pipa ketel uap yang menunjukkan bahwa dengan beban listrik (MW) yang sama dihasilkan pembangkit dimulai tanggal 16 Januari, terlihat total pemakaian air pengisi, sistem air penambah dan pemakaian batubara yang lebih tinggi diatas normal. Hal ini ditunjukkan dari nilai deviasi yang ada beberapa hari sebelum diputuskan unit berhenti beroperasi (stop unit), dilanjutkan dengan inspeksi pada beberapa area ketel uap dan pemotongan material gagal untuk dibandingkan dengan material standar SA-210C.

\section{Hasil Dan Pembahasan}

\subsection{Pengukuran diameter dan ketebalan}

Pengukuran ketebalan pada sampel dilakukan searah jarum jam (clockwise) dengan titik awal dimulai dari lokasi 1-8 dengan menggunakan micrometer sebagai alat ukur.
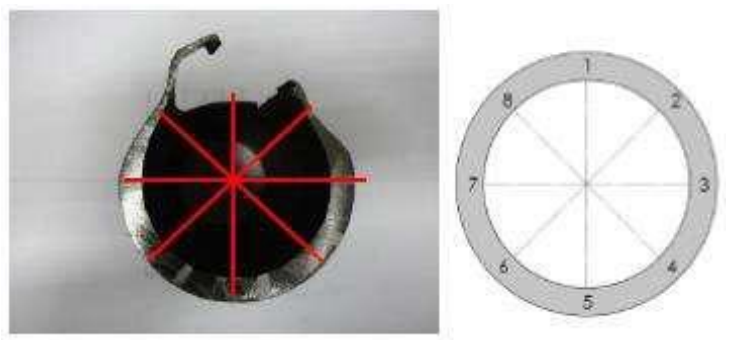

Gambar 1. Titik pengukuran ketebalan dan penentuan lokasi

Hasil pengukuran menunjukkan, pada lokasi 1 yang merupakan sampel terjadinya kegagalan material, mengalami pengurangan ketebalan yang paling tinggi, 2,69 mm diikuti pada lokasi 2 dan lokasi 8 dengan nilai pengurangan ketebalan 2,45 mm dan 2,24 mm. Adapun lokasi yang paling kecil mengalami pengurangan ketebalan terdapat pada lokasi 4 dan lokasi 6 , dengan nilai pengurangan ketebalan $0,1 \mathrm{~mm}$. 
Journal of Mechanical Engineering and Mechatronics ISSN: 2527-6212, Vol. 3 No. 1

(C) 2018 Pres Univ Press Publication, Indonesia

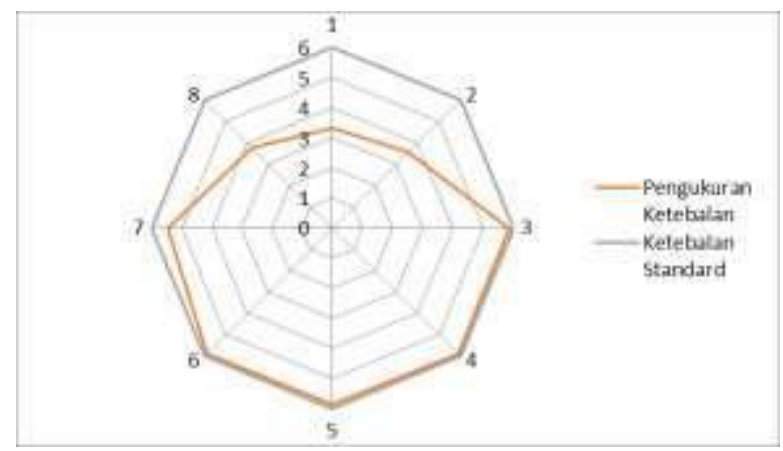

Gambar 2. Perubahan nilai ketebalan terhadap ketebalan standar

Perubahan ketebalan ini dianalisa akibat korosi erosi dari semburan uap bantu dalam pengoperasian sootblower dimana lokasi 1 merupakan lokasi pipa menerima secara langsung semburan uap bantu (auxiliary steam) dari sootblower.

Tabel 5. Laju korosi pada lokasi pengamatan

\begin{tabular}{|c|c|c|c|c|c|}
\hline \multirow{2}{*}{ Lokasi } & \multicolumn{2}{|c|}{ Ketebalan (mm) } & \multirow{2}{*}{$\begin{array}{l}\text { Service Life } \\
\text { (days) }\end{array}$} & \multirow{2}{*}{$\begin{array}{c}\text { Pengurangan } \\
\text { Ketebalan }\end{array}$} & \multirow{2}{*}{$\begin{array}{c}\begin{array}{c}\text { Laju Korosi } \\
\text { (mm/day) }\end{array} \\
(\mathrm{mm})\end{array}$} \\
\hline & $\mathrm{t}_{1}$ & to & & & \\
\hline 1 & 3,31 & 6 & 391 & 2,69 & 0,00688 \\
\hline 2 & 3,55 & 6 & 391 & 2,45 & 0,00627 \\
\hline 3 & 5,87 & 6 & 391 & 0,13 & 0,00033 \\
\hline 4 & 5,9 & 6 & 391 & 0,1 & 0,00026 \\
\hline 5 & 5,86 & 6 & 391 & 0,14 & 0,00036 \\
\hline 6 & 5,9 & 6 & 391 & 0,1 & 0,00026 \\
\hline 7 & 5,46 & 6 & 391 & 0,54 & 0,00138 \\
\hline 8 & 3,76 & 6 & 391 & 2,24 & 0,00573 \\
\hline
\end{tabular}

\subsection{Pengujian komposisi kimia material}

Tabel 6. Pengujian komposisi kimia sampel material gagal

\begin{tabular}{|l|c|c|c|}
\hline \multicolumn{1}{|c|}{ Komposisi Material } & Unit & SA-210C & Sampel \\
\hline \hline Carbon (C) & $\%$ & 0.27 & 0.101 \\
\hline Silicon (Si) & $\%$ & 0.10 & 0.335 \\
\hline Mangan (Mn) & $\%$ & 0.93 & 0.591 \\
\hline Tembaga (Cu) & $\%$ & - & 0.037 \\
\hline Nickel (Ni) & $\%$ & - & 0.03 \\
\hline Mobilidium (Mo) & $\%$ & - & 0.262 \\
\hline Chrom (Cr) & $\%$ & - & 0.931 \\
\hline Vanadium (Va) & $\%$ & - & 0.218 \\
\hline Titanium (Ti) & $\%$ & - & 0.002 \\
\hline Alumunium (Al) & $\%$ & - & 0.04 \\
\hline Fosfor (P) max. & $\%$ & 0.048 & $<0.003 * *$ \\
\hline Sulfir (S) max. & $\%$ & 0.058 & $<0.003 * *$ \\
\hline \multirow{2}{*}{$*$ Pengujian } & Standard & ASTM A751/ASTM E415 \\
\cline { 2 - 5 } & Mesin Uji & Optical Emission Spectrometer \\
\hline
\end{tabular}

Berdasarkan tabel 6 ditunjukkan bahwa sampel material gagal memiliki nilai karbon (C) dan mangan (Mn) dibawah nilai standar desain SA-210C dengan selisih nilai $0,169 \%$ untuk karbon dan 0,339\% untuk mangan. 


\subsection{Pengujian kekerasan sampel material gagal}

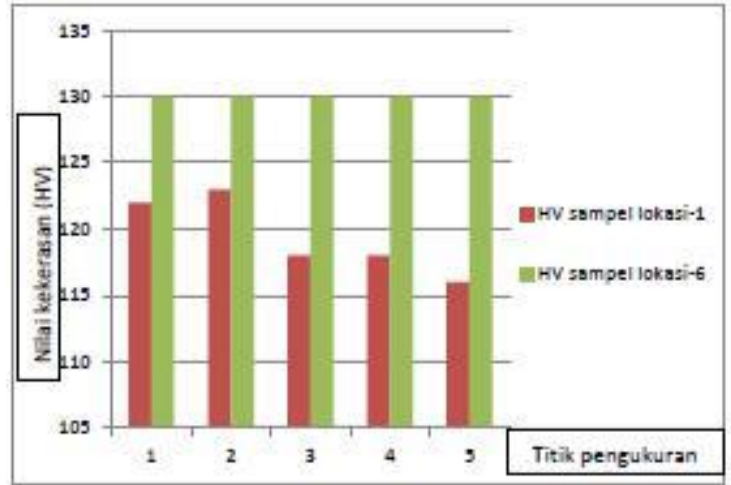

Gambar 3. Pengukuran kekerasan sampel lokasi 1 dan sampel lokasi 6

Berdasarkan gambar 3 ditunjukkan nilai kekerasan sampel pada lokasi 1 lebih kecil dibandingkan nilai kekerasan pada lokasi 6 , dengan selisih nilai rata-rata $10.6 \mathrm{HV}$. Perbedaan nilai kekerasan ini sangat dipengaruhi oleh persentase unsur karbon (C) dimana sampel pada lokasi 1 memiliki unsur karbon yang lebih kecil dibandingkan sampel pada lokasi 6.

\subsection{Pengujian struktur mikro material}

Hasil pengamatan gambar 4 untuk struktur mikro material standar (lokasi 6), yaitu:

a. Struktur mikro ferrit

b. Jumlah perlit (sementit dan ferrit) banyak c. Sedikit mikro crack

d. Pengamatan ukuran butir perlit banyak dan halus

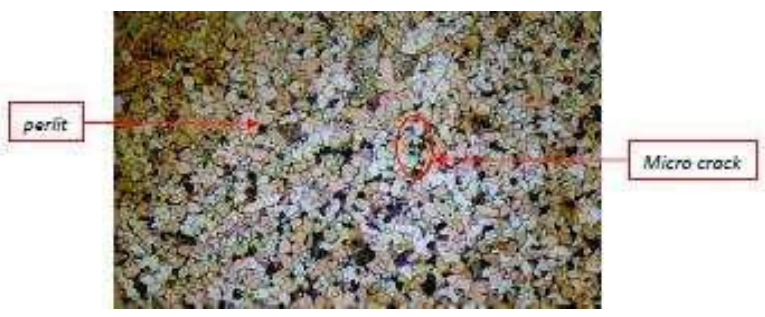

Gambar 4. Pengamatan struktur mikro dilokasi 6

Hasil pengamatan gambar 5 untuk struktur mikro material yang gagal (lokasi 1), yaitu:

a. Struktur mikro ferrit

b. Pengamatan ukuran butir sementit besar dan banyak

c. Pengamatan mikro crack banyak

d. Pengamatan ukuran butir perlit sedikit dan tidak halus

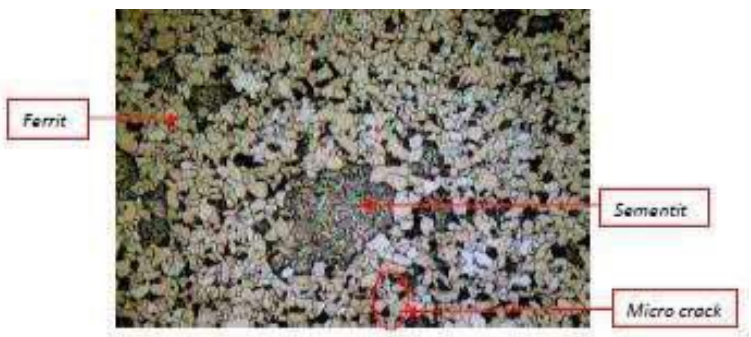

Gambar 5. Pengamatan struktur mikro dilokasi 1

\subsection{Perhitungan tekanan internal maksimum pada pipa}

Penipisan akibat degradasi suatu material, mengakibatkan perubahan batasan operasi material tersebut menerima gaya atau tekanan maksimum, baik dari dalam maupun luar. Terjadinya korosi erosi pada masing-masing lokasi pipa, mengakibatkan 
terjadinya perubahan penipisan untuk itu dilakukan perhitungan tekanan internal maksimum $^{[2]}$ yang diizinkan.

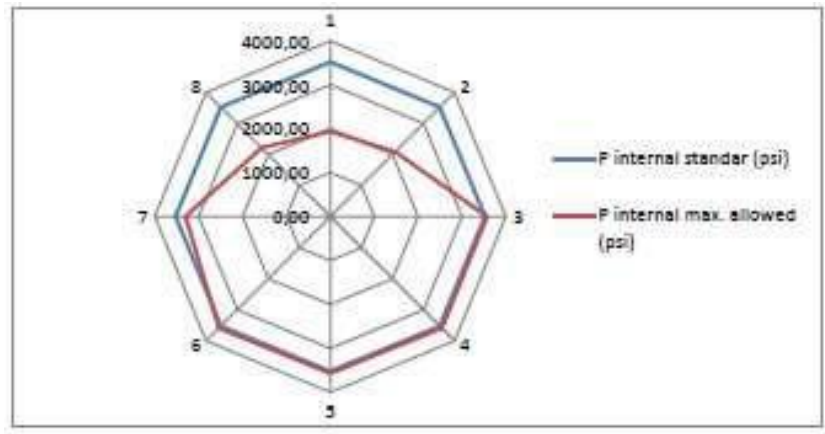

Gambar 6. Perhitungan tekanan internal maksimum akibat perubahan ketebalan

Berdasarkan perhitungan dapat dilihat bahwa tekanan internal maksimum untuk ketebalan pipa standar yaitu 3524.77 psi atau 24.30 MPa. Perubahan ketebalan pada lokasi 1 dengan kondisi pengukuran ketebalan 0.130083 inci hanya diizinkan mendapat tekanan internal maksimum sekitar 1938.57 psi atau 13.36 MPa. Kegagalan material SA210C ini dianalisa akibat tekanan internal maksimum fluida yang melewati pipa pada lokasi 1 melebihi perhitungan yang diizinkan, dengan penyebab perubahan ketebalan masing-masing lokasi akibat korosi erosi.

\section{Kesimpulan}

Kegagalan material SA-210C sebagai pipa superheater karena korosi erosi. Penipisan ketebalan pipa dari $6 \mathrm{~mm}$ menjadi $2.69 \mathrm{~mm}$ (pada lokasi 1) menyebabkan pipa tidak mampu lagi menerima tekanan uap utama (main steam pressure), sehingga pipa mengalami kegagalan (failure). Korosi erosi yang terjadi dikarenakan kandungan oksigen (O) dari uap semburan sootblower bereaksi dengan unsur besi $(\mathrm{Fe})$ pada permukaan pipa, sehingga terbentuknya senyawa $\mathrm{FeO}$. Terbentuknya senyawa $\mathrm{FeO}$ pada pipa ini perlahanlahan akan terlepas akibat semburan uap dari sootblower yang terus- menerus. Terbentuknya $\mathrm{FeO}$ dan terlepasnya $\mathrm{FeO}$ berulang-ulang pada permukaan pipa membuat pipa mengalami penipisan yang dikenal sebagai korosi erosi.

\section{Daftar Pustaka}

Muchlis, Moch. (2004), Proyeksi kebutuhan listrik PLN tahun 2003 s.d. 2020.

ASME (2007), Boiler \& Pressure Vessel Code Section VIII, Division I.

Electric Power Research Institue (EPRI) (1996), Water chemistry fossil fuel power plant corrosion.

Chubu Electric Power (2011), Thermal efficiency improvement of existing thermal power plants in foreign countries.

Purbolaksono, J. (2009), Literative technique and finite element simulation for supplemental condition monitoring of water tube boiler.

Anne, Z., (2009), Dasar-dasar analisa kegagalan, Departemen Metalurgi dan Material, Fakutas Teknik Universitas Indonesia.

French, N. (1992), Metallurgical failure in fossil fired boiler, New York: Jhon Wiley \& Sons, Inc.Viswanathan, R. (1993), Damage mechanisme and life assesment of high temperature components, ASM linternational.

Zuliardie, R. (2004), Hubungan besar butir dengan kekuatan dan kekerasan pada logam aluminium, Jurnal R \& B Vol. 4 No.1.

Andi, R. (2013), Korosi pada pembangkit thermal, Departemen Metalurgi dan Material, Fakutas Teknik Universitas Indonesia.

Agus, Suhartono (2004), Pengaruh ukuran butir terhadap kuat fatik baja, Prosinding semiloka teknologi simulasi dan komputasi serta aplikasi. 